\title{
O DESTINO DESENHA A DESUMANIZAÇÃO EM OS DESVALIDOS
}

\author{
Marta Morais da Costa *
}

inqüenta e cinco anos depois ecoa a notícia : "Lampiããããão morreeeeu!...". ${ }^{1}$ Não mais nos ares mas nas letras do Nondeste, ressuscitando figuras históricas agora travestidas em seres de papel, com igual força e mais lastimável realidade. $O$ assassinato do bando de Lampião no ano de 1938 em Angico (SE) assentou o golpe de misericórdia na estrutura coronelística do sertão brasileiro, invadido pela modernização da vida social e econômica que se, aparentemente, renova as relações entre homens e instituições, não erradica a camada, diariamente acrescida, dos desvalidos da História.

Eles são muitos e são tantos que não cabem todos nas pouco mais de duzentas páginas de Os Desvalidos (1993), romance de Francisco Dantas , mas deixam nelas a contundência irresgatável de sua marginalização e de sua desumanização. Ressurgem como espectros de dedo em riste a acusar a história - e a nós como seus fazedores - pela inescapável vida de tormentos, medos e frustrações a que se viram jungidos à total revelia. Um vendaval de perdas e quedas arrasa as personagens que, embora dotadas de ralas oportunidades de

* Universidade Federal do Paraná

1 DANTAS, Francisco. Os Desvalidas. Sāo Paulo : Companhia das Letras, 1993. p. 11. Todas as citações identificadas pela página indicada entre parénteses pertencem a esta edição. 
fuga ao círculo de ferro da destruição, cumprem um destino traçado por mãos alheias e insensíveis o qual só confirma a caminhada rumo à anulação. Ao prefixo de negação des-, presente no título, vem somar-se a morte de Lampião, primeira frase do romance, construindo o prenúncio de invalidação contínua das existências representadas no texto.

O narrador se compraz em acumpliciar o leitor para seguir uma personagem privilegiada: Coriolano, um "pobre diabo" no dizer de José Paulo Paes $^{2}$. Identificado por um nome que evoca o couro, matéria-prima de seu sustento, transformado em metáfora de sua condição de animalização pela perda continuada da validez humana. Corresponde também ao paralelo estabelecido com a personagem da tragédia homônima de Shakespeare, banida de sua terra por representar uma nova perspectiva da relação do homem com o poder:

The fundamental insight that this play embodies is that political and social forms cannot be separated from, are in fact judged by , the human and moral qualities that shape them, and the human and moral qualities that they foster.

O cônsul Caio Márcio Coriolano é o indivíduo que carrega como apêndice a seu nome o topônimo de sua terra natal, Coríolos, como o novo cônsul banido, Coriolano remendão, guarda em si Aribé, origem abandonada na busca por outra vida, menos amarga.

Em Coriolano se integram perspectivas políticas, sociais e humanas que o narrador transfere às demais personagens, imantando-as de complexidade. Filipe, Lampião, Maria Melona e Coriolano são entrecruzados por um discurso que esmiuça suas identidades interiores, revelando faces poliédricas que conduzem o leitor por desvãos de caráter, por sonhos recônditos, por temores inconfessados.

Lampião estranho rei corrido e engendrado pela penúria de seu próprio povo (p.150), desveste sua face belicosa para apresentar-se, nu e lírico, no envolvimento subversivo de seu amor por Maria Bonita, a múltipla Maria Alcina, Maria de Déia e Santinha, quatro nomes tão poucos para contê-la (p.150). Essa postura do narrador, prismatizando a figura ficcional e criando p.6-5.

2 PAES, José Paulo. Francisco Dantas e o pobre-diabo. Folha de São Paulo, São Paulo.

3 THE AGE of Shakespeare. Middlesex, England : Penguin Books, 1966. p.253. Tradução minha: "A perspectiva fundamental que a peça corporifica é que formas políticas e sociais não podem ser separadas, sāo de fato julgadas por elas, das qualidades humanas e morais que as modelam e das qualidades humanas e morais que tratam." 
subterrâneos de sentidos para as pessoas históricas aparece também na excepcional criação de Maria Melona - também ela múltipla: Zé Queixada e Saitica - protagonista de uma saga de sedução, amor e morte. Maria Melona, uma Diadorim de cabeça para baixo no seu exterior, mulher que se traveste em homem, para voltar a ser - Diadorim restituída - um abismo de paixão vital e movediça, envolvendo e abrigando o amor único e titubeante de Filipe.

Este, um "amigo de cavalos", vocação identificada na etimologia de seu nome, transfere da montaria para a carga a paixão desmedida e fetichista por brilhos e metais. Um ser feito de tímida ternura e profunda obsessão, tratado pela vida com o mel das vitórias que, logo, logo, trava a boca, convertido em dano irreparável. Personagem caprichosa, como seu destino, que se enreda nas malhas do sucesso social e econômico para liberar-se, finalmente, na teia dos quiméricos brilhos de metais privativos.

Ungido pelo privilégio que lhe conferem os olhos do sobrinho Coriolano, Filipe ganha ossatura, músculos e sedução com o desenrolar do fio da memória do tamanqueiro remendão. Cresce e se robustece enquanto criação ficcional, ganhando espaço e independência dentro da narrativa, centralizando conflitos e episódios com o poder magnetizador de suas qualidades ficcionais. Sua irrupção na história de Coriolano, já na primeira parte do romance, é mediada pela lembrança dos "olhos envidrando na carinha de Filipe" (p.18), no episódio do alpendre da hospedaria no Aribé. Ela se completa ao final do quarto capítulo para ocupar inteiramente os fragmentos 5 e 6,9 a 12 da primeira parte, finalizando o romance como símbolo do desatino e da fidelidade. Seu tipo suave e franzino, representado inclusive pela sonoridade de seu nome, assume o necessário contraponto à rudeza de Zerramo, à violência de Lampião e ao caiporismo de Coriolano. Dono de "falinha de azougue e natureza velada" (p.29) converte-se ao final do romance num exemplo da destruição humana: "entre doce e soberano, desapagado deste mundo na sua postura ausente de fantasma" (p. 219), "um bicho sestroso" (p.220), que demonstra no comportamento exterior sua persistência em sobreviver. Entretanto, sozinho, à noite, às escondidas, renasce como o "rei dos montadores" (p.221) tornando-se o símbolo da "irreco-nhecivel bandeira de algum país destroçado" (p.221).

Em igual evolução rumo ao aniquilamento, as demais personagens espalham-se pelas páginas do romance: Chico Gabiru, figura pouco humana "como um morcego" (p.14); Zerramo, o da "coragem selvagem" (p.18); João Coculo, o pai, autoridade inabordável (p.143), morrendo sozinho e servindo de pasto às varejeiras; Cantílio, o barbeiro, irmão de sina de Coriolano, "destroços de alguma ventania que passou, rebotalhos, sobras, sobreviventes" (p. 82); Maria Melona, a da "bochecha afolozada", acabando-se estuprada e "retalhada a facadas, oferecida de bandeja aos urubus" (p.216); e Lampião, rei corrido, 
sempre traído, ser encantado na voz de seu povo, sonhando com um "mundo diferente, sem cerca e sem traição, sem cancela e sem persiga" (p.186), morrendo decapitado em Angico. Esse bando de seres desvalidos, desenraizados, perseguidos pela "vidinha caipora" (p.101) que a cada um reserva um quinhão de desgraça, como se quisesse atestar a impossibilidade de futuro a quem não nasceu aquinhoado pela fortuna: "É a sina que iguala todos nós, conforme o quilate de cada um: ou a morte, que nem aconteceu com o compadre Zerramo, ou senão a fome e o rebaixamento.(...) Pose, minha gente, quem tira e bota é o zinabre do dinheiro! O resto é conversa fiada! " (p.86-7). Para um desvalido, "a vida se reduz a titica de galinha" (p.19).

Coriolano, protagonista dessa tragédia de anulação, se vê reduzido à miséria gradativamente. Carrega duas culpas que necessitam de purgação: o abandono do "aconchego do pai e a terra do seu lugar" (p.144) e "a injustiça que fez a Maria Melona. Essa é a minha mancha".(p. 172). Figura investida de distinção molesta, o corcunda Coriolano porta até no seu aspecto físico uma deformação que parece traduzir visualmente "a má sorte (...) trança de seu destino" (p.207), na contramão do herói modelar de narrativas antigas. Seu calvário de desenraizado realiza a predição paterna: "Já viu pedra que se muda criar limo? Hein, Coriolano? Não sabe que formigão bate asa é pra se perder, hein ?" (p. 144). Tal como um oráculo a vaticinar desgraças futuras, João Coculo deixara traçado o caminho do desvalimento do filho. Predição essa que se encontra deslocada temporalmente na enunciação do romance, pois aparece apenas na segunda parte, onde vê convertida sua função premonitória em confirmação inexorável. É exatamente a inevitabilidade que torna mais contundente a cosmovisão representada no texto. A engrenagem da injustiça, da violência, do medo, da pobreza e da desumanização tritura os desprotegidos, reservando apenas aos coronéis - monarcas treitentos que chupam o sangue da pobreza e nunca se aquietam, achando pouco a ruma de possuidos (p.151) ao govemo e à "firma graúda" (p.28) as gostosuras da vida. O desequilíbrio social é a mola mestra do banditismo e do desamparo, levando Cantílio a ironizar: "Arte por estas bandas, meu irmão, só se for a de furtar!" (p.83).

A trajetória individual do "pobre diabo" em busca da purificação de suas culpas cruza-se com o embate entre as forças sociais, conferindo ao romance faces múltiplas de compreensão. E não falta ao texto o quadro social de um tempo de mutaçōes em que as "primeiras foticas puxadas a gasolina" (p. 46) viajam pelos caminhos do interior do Brasil; em que as boticas artesanais sã̉o substituídas pelas farmácias sustentadas pelas "firmas graúdas" e pelos remédios industrializados; em que a força policial repressora, apoiada na lei, caça os últimos cangaceiros, dando fim ao ciclo desses heróis livres; em que o capital se afirma como instrumento do poder, transformando em comerciais as 
relações humanas e estratificando, cada vez mais imutavelmente, as classes sociais a partir do "zinabre" do dinheiro e para cuja distinção contribui, de maneira perversa, a inflação: "A coisa está ruim (...) cada dia mais o cobre escorrega das mãos e ninguém sabe onde se entoca ! É o diabo da carestia! (p.50).

Coriolano bem que tentou se inserir nesta sociedade, abandonando a agricultura e se transformando em comerciante, primeiramente na botica, depois no fabrico de bombons para, falido nos dois negócios, enveredar para a prestação de serviços como seleiro artesão. Em nada conseguiu sucesso, derrotado sempre pela força da industrialização e da produção em série. A volta à terra natal o tornou falido como agricultor mas bem sucedido como estalajadeiro: desta feita foi a estrutura arcaica e feudal do cangaço que o derrotou. Vítima da velha e da nova conjuntura econômico-social, sem saída e sem discernimento, atribui a Lampião, um desvalido como ele, toda a culpa. Este erro estratégico configura de maneira cruel a derrocada da classe média sertaneja, para a qual o futuro inexiste porque o presente foi aniquilado por derrotas sucessivas: o medo, a violência e a perversa estrutura de entredevoramento de iguais.

O sucesso de Janjão Devoto, porém, apontava o caminho: "bodegueiro forte e manhoso", "parcimonioso em despachar mercadoria a fiado", "finório [que] chega a passar goma de tapioca nos tecidos quebradiço pra que pareçam encorpados e duráveis", demonstrando "acinte declarado a quem vive na pobreza", em suma, um "safado"(p. 117-121). Coriolano, ao comparar seu destino ao de Janjão Devoto, não pode deixar de emitir o resultado de sua reflexão: "Por que diabo será que esses caprichos afrontosos e tão declarados, não pegam em gente mal-procedida, em bodegueiro safado, e só prejudicam mesmo quem tem algum engenho por dom, ou vive a cuidar de sua arte? Negocinho invocado!" (p. 121).

A diferença entre os comerciantes mais se acentua no contraponto com a profissão decadente de Filipe, vendedor nômade, a oferecer "alfinetes, agulhas, grampos de cabelos, espelhinhos e outras reles miudezas" a quem todos repelem "por temor, asco, remorso, ou qualquer outro insultuoso motivo de aversão"(p. 218). Mas é a este último - "cavaleiro", "trágico palhaço", "bicho espantado" - que o narrador atribui ares de "rei dos montadores" e "meninão maravilhado", capaz de, através da loucura, testemunhar as venturas de uma outra sina, perdida na realidade e resguardada num gavetão "de metais de antiga estimação" (p. 220).

Retomando a tradição do romance regional do Nordeste, engrandecido pela riqueza e plasticidade do discurso literário de Guimarães Rosa, Francisco Dantas consegue reavivar esse tipo de narrativa, oxigenando-lhe a estrutura pela 
retomada da não-linearidade, do discurso indireto livre, da introspeç̧ão das personagens, da denúncia social, somados a frases opulentas e grávidas de figuras, e às contradições inerentes às figuras humanas, aos fatos e ao contexto social.

A estas características vem somar-se a condução madura e envolvente da narração que, ludicamente, alterna diferentes marcos temporais, ocupa $e$ descobre, cada uma a sua vez, as consciências das personagens diversas e mantém, ao longo do romance, a atmosfera opressiva e trágica necessária ao bem contar a derrocada dos desamparados.

As três partes do romance, desiguais em extensão, intenção, temporalidade e gênero, procuram assinalar sua particularidade já nos títulos: "O cordel de Coriolano", "Jomada dos pares no Aribé" e "Exemplário de partida e de chegada".

O cordel de Coriolano não passa de tentativa fracassada de transpor as memórias ao papel. Os principais empecilhos, reconhecidos pela própria personagem, são a inexperiência em "botar em versos uma história limpa $e$ vendadeira" (p.20) e a força avassaladora das leituras habituais em sua mocidade que se imiscuíam na forma de narrar, mesmo contra sua vontade:

(..) parece que se viciara na leitura de tanto descalabro e muita inventação, pois quanto mais se empinava em direiteza, caprichando em espremer e tornar enxutas as suas exatidões, mais era traído pelo chamado da rima, e a coisa saía desenxabida, desaceriada com a pisada do tom (p.21).

Neste fragmento metaficcional ecoa a luta do artista em "encoivarar as primeiras linhas" na busca incessante de "termos que chamegassem de vida" (p. 21). E o que predispunha Coriolano a desejar transcrever em versos sua história? Em primeiro lugar, sua competência como leitor que, em anos distantes fora capaz se reproduzir de memória $A$ vida de Cancáo de Fogo e seu testamento e Os doze pares de França e, em tempos mais recentes, quando estalajadeiro no Aribé, lia para os visitantes As mil e uma noites, Os doze pares de França, "sempre arrematando por um folheto de Romano" (p.170). Exposta pelo texto, a história do leitor Coriolano delimita as condições de sua escrita, ao mesmo tempo em que explicita os propósitos de sua criação verbal e os caminhos de seu imaginário: o popular, a gesta heróica e o relato de sofrimentos.

Marlyse Meyer, em estudo sobre a literatura de cordel ${ }^{4}$, distingue essa produção em dois tipos: o folheto - geralmente textos curtos de 4 a 16 páginas

4 AUTORES DE Cordel. Sel. de textos e estudo crítico por Marlyse Meyer. São Paulo : Abril Educação, 1980. p.98. 
- e os romances, mais longos e que podem chegar a 64 páginas. Ambos recebem a denominação de cordel. Entre os romances, sobressai o de sofrimento que narra as desgraças do protagonista, que, "fiel ao seu amor, ou vítima de calúnias, ou do destino (...) ao fim de tudo (...) será exaltado e os opositores humilhados na sua soberbia".

A pretensão de Coriolano ao narrar o acontecido e as desgraças decorrentes aponta para esse "romance de sofrimento" que, ao final, para maior pesar do novel escritor, não se concretiza. " O cordel de Coriolano" se converte numa descrição que não se sustenta na tradição popular, de vez que $O s$ Desvalidos é, sobretudo, (...) "o registro por assim dizer elegiaco do romance da desilusão e do malogro em cuja órbita gravita o romance do pobre-diabo" ${ }^{6}$

A contradição, uma das vigas-mestras do romance de Francisco Dantas, se faz presente mesmo no nível metaficcional pois o narrador Coriolano acaba contido por uma outra voz que o enquadra numa saga de fracassados, malgrado sua tendência em escrever em versos a história de heróis. $O$ grito que ecoara na abertura do "Cordel" como um prenúncio de libertação ao anunciar a morte de Lampião, se faz gesto desvairado e som de passos sem prumo nem rumo ao findar a terceira e última parte do romance: "Perde o prumo, também por força da cabeça turbulenta, e prossegue trambecando, jambengo, adernando em cima do brodão" (p.216). E a gesta se esvai na anulação.

A segunda divisão de Os Desvalidos, "Jornada dos pares no Aribén, mantém a ligação com a literatura de cordel ao estabelecer - via o vocábulo pares - o anúncio de feitos de bravura como os d' Os doze pares de França, um dos "livros do povo". ${ }^{7}$ Novamente o narrador ludibria o leitor: a valentia dos nobres de Carlos Magno é, no sertão, a coragem da sobrevivência. Todos se vêem desafiados pela terra, pelos homens, pelo sistema sócio-econômico, pelas dificuldades do momento histórico a travar batalhas menos gloriosas e mais pragmáticas. Tirar do solo o sustento, do trabalho minguado o "dinheirinho" e da vida ralas alegrias. Os pares do Aribé - Coriolano, Filipe e Zerramo vêem-se obrigados a enfrentar um igual na sorte, embora desigual na morte, Lampião. Como todos os cangaceiros, ele também, carente "das necessidades mais rudimentares e indispensáveis a qualquer vivente" (p.111). A batalha em que os iguais se anulam é, no romance, o quadro mais contundente de

5 LITERATURA POPULAR em verso: antologia. Sel. introd. e comentários Manoel Cavalcanti Proença. Belo Horizonte : Itatiaia; São Paulo : EDUSP; Rio de Janeiro : Fundação, Casa de Rui Barbosa, 1986. p.29-30.

6 PAES, José Paulo. Francisco Dantas e o pobre-diabo. Folha de São Paulo, São Paulo, p.6-5, 26 set. 1993.

7 CASCUDO, Luís da Câmara. Cinco livnos do povo. 2. ed. fac-similada. Joẽo Ruoaa : Editora Universitária, 1979. 
autodevoração social em que os vencedores - qual deles : quem mata? quem sobrevive? quem morre ? - aparecem como Pirros redivivos no sertão sergipano.

A terra natal se mostra mãe e madrasta: acolhe Coriolano, o filho pródigo, não com festas mas com a exigência de suores e desenganos. Cumprida a pena, ela o premia com curto período de paz para, novamente, como uma espécie de Parca implacável, expulsá-lo em definitivo. Para que essas reviravoltas possam ocorrer, o tempo se estende além de um único dia, como o termo jornada fazia supor.

Para que possa se tornar adequada aos acontecimentos narrados, a jornada precisa ser entendida com o sentido que lhe atribuía o teatro medieval: representa cada um dos atos do espetáculo, ou seja, uma seqüência de ação completa e unitária. O título dessa segunda parte contém, portanto, indicadores de sentido que a qualificam claramente como um universo antigo, de uma terra prometida e perdida para sempre.

O terceiro subtítulo - "Exemplário de partida e de chegada" - não esconde sua relação com o universo da escrita. Exemplário é "o livro ou coleção de exemplos ${ }^{\prime 8}$ Como nos folhetos e nos romances de cordel, o encaminhamento do texto conduz, ao final, na exposição da moralidade da história lida, para uma conclusão de ordem moralizadora. Mas os exemplos apontados pelo livro não podem ser de maior desvalimento. A gesta anunciada na intenção do cordel da primeira parte se converte, definitivamente, em antigesta, como quer José Paulo Paes. Reencontram-se os dois "pares" sobreviventes: Coriolano, "tão novo ainda... e já assim acabadinho" (p.213), "remoendo a vida com fuga, numa leseira sem nervo, o juizo destornado" (p.214) e Filipe, "abestalhado, de tutano amolecido na cachola, parece ter perdido o faro para as reações mais rudimentares e sinalizadoras do rebanho humano" (p.217).

Cumprida a saga de anulação humana, esses bichos sobrevivem de teimosos, o primeiro, no sonho de voltar ao Aribé mas pregado, como os tamancos que fabrica, a Rio-das-Paridas; o segundo, renascendo, "meninão maravilhado ", nos brilhos de metais antigos, corroídos pelo azinhavre, desviados de sua serventia funcional e convertidos em objetos de luz.

Um exemplário que aponta com insistência e inapelavelmente para a entrada do Inferno, onde os caminhantes deixam toda a esperança, no dizer de Dante Alighieri.

É inevitável a associação de Os Desvalidos com Grande Sertão: Veredas, de Guimarães Rosa. Ambos apontam para o "fim da nossa idade-média

8 FERREIRA, Aurélio Buarque. Nowo dicionário da língua ponuguesa. Rio de Janeiro: Nova Fronteira, [s.d.] p.596. 
sertânica" ${ }^{9}$, ambos convertem a pesquisa formal romanesca e de linguagem na espinha dorsal de seu discurso ficcional. No caso de Os Desvalidos tal posição diante da escrita tem duplo valor literário :

(...) serve de corretivo a certo abastardamento vernacular da nossa prosa de fição mais recente como [ demonstra ] , com a prova insofismável da sua qualidade literária, que o filão da ficção nordestina de 1930 tem ainda o que oferecer a quem saiba lavrá-lo com engenho e arte. ${ }^{10}$

A crítica de José Paulo Paes vem indicar uma posição ambivalente para o romance de Francisco Dantas. Em primeiro lugar, sua inserção numa linhagem riquíssima da narrativa brasileira, o regionalismo. Filiando-se ao regionalismo crítico de Graciliano Ramos e à compreensão de que "os conteúdos sociais e psicológicos só entram a fazer parte da obra quando veiculados por um código de arte que lhes potencia a carga musical $e$ semântica" ${ }^{\text {"l }}$, Os Desvalidos olha para o passado literário - a literatura popular e o regionalismo de 30 - , para as conquistas da ficção moderna - o diálogo indireto livre, a quebra da linearidade temporal, a investigação do inconsciente, a contradição como mola mestra da conduta das personagens, a paródia, a metaficção - , olha ainda para a realidade social injusta, para a superação de relações econômicas arcaicas, para a história dos vencidos. Busca nos caminhos já trilhados pelo romance brasileiro, as potencialidades ainda não de todo esgotadas. Forças que se revelaram capazes de construir um texto contundente, desvendador e moderno.

\section{RESUMO}

O romance OS Desvalidos, de Francisco Dantas, retoma o filão da ficção regionalista de 1930, acrescendo, porém, um estrutura moderna e um trabalho apurado com a linguagem. Retrata a vida no sertão de Sergipe ao final dos anos 30 a partir da

9 OLIVEIRA, Franklin de. Guimarães Rosa. Ir.: COUTINHO, Afrânio (org.) $A$ literatura no Brasil. 2.ed. Rio de Janeiro : Sul Americana, 1970. v.5, p.404.

10 PAES, Francisco Dantas, p.6-5.

11 BOSI, Alfredo. Histónia concisa da literatura brasileira. 3. ed. São Paulo: Culırix, 1981. p.485. 
ótica dos desamparados pelo destino. Suas personagens caminham inevitavelmente rumo à destruição e à desumanização, retratadas por um texto de profunda contundência, acentuada pela linguagem inusitada e envolvente.

Palavras-chave: Francisco Dantas, Ficção brasileira contemporânea, Regionalismo

\section{RÉSUMÉ}

Le roman Os Desvalidos, de Francisco Dantas, reprend le chemin de la fiction régionaliste de 1930, en y ajoutant, cependant, une structure moderne et un travail épuré avec le langage. Il réproduit la vie à l'intérieur de l' état de Sergipe à la fín des années 30 à partir de la perspective des abandonnés par le destin. Ses personnages marchent inévitablement vers la destruction et l'imhumain, représentés par un texte profondement contondant, agrandi par un langage incommun et entraînant.

\section{REFERÊNCIAS BIBLIOGRÁFICAS}

AUTORES DE CORDEL. Sel. de textos, estudo crítico por Marlyse Meyer. São Paulo : Abril Educação, 1980.

BOSI, Alfredo. História concisa da literatura brasileira. 3. ed. São Paulo : Cultrix, 1981 .

CASCUDO, Luís da Câmara. Cinco livros do povo. 2. ed. fac-similada. João Pessoa : Editora Universitária, 1979.

DANTAS, Francisco. Os Desvalidos. São Paulo : Companhia das Letras, 1993.

FERREIRA, Aurélio Buarque de Holanda. Novo dicionário da lingua portuguesa. Rio de Janeiro: Nova Fronteira, [s.d.]

LITERATURA POPULAR EM VERSO: antologia. Sel. introd. com. Manoel Cavalcanti Proença. Belo Horizonte : Itatiaia; São Paulo : EDUSP; Rio de Janeiro : Fundação Casa de Rui Battosa, 1986.

OLIVEIRA, Franklin de. Guimarāes Rosa. In: COUTINHO, Afrânio (org.) A literatura no Brasil. 2. ed. Rio de Janeiro : Sul-Americana, 1970. v.5

PAES, José Paulo. Francisco Dantas e o pobre-diabo. Folha de São Paulo, São Paulo. p.6-5, 26 set. 1993.

THE AGE Of Shakespeare. Middlesex, England : Penguin Books, 1966. 